\title{
Profile of Patients with Amyotrophic Lateral Sclerosis Across Continuum of Care
}

\author{
Vahe Kehyayan, Lawrence Korngut, Nathalie Jetté, John P. Hirdes
}

\begin{abstract}
Objective: This study describes the socio-demographic and clinical profile of persons with amyotrophic lateral sclerosis (ALS) in home care, nursing homes and complex continuing care settings in several Canadian jurisdictions. Methods: A cross-sectional study was conducted using available Resident Assessment Instrument (RAI 2.0 and RAI Home Care) national databases from 19962011. The profile of ALS patients was compared with patients without pre-specified neurological conditions. Results: There were 2,092 ALS patients identified in these settings. Persons with ALS were more likely than those in the comparison group to suffer from health instability (25.4\%) and minor to major depressive symptoms (27.2\%), to experience falls (44.0\%) and weight loss (22.9\%), to require extensive assistance in activities of daily living (54.9\%), and to receive rehabilitation services: physical (23.9\%), speech language pathology (8.9\%), and occupational therapy 43.3\%). Conclusions: The ALS population in this study are greatly affected by a number of health issues. They are more likely than the comparison group to require therapies, medical interventions, and psychotropic drug use. While persons with ALS have a poor prognosis, a great deal could be done to enhance their quality of life and the quality of care they receive.
\end{abstract}

RÉSUMÉ: Profil des patients atteints de sclérose latérale amyotrophique dans l'ensemble des différentes étapes de soins. Objectif : Cette étude décrit le profile sociodémographique et clinique d'individus atteints de sclérose latérale amyotrophique (SLA) qui reçoivent des soins à domicile, en établissement de soins prolongés ou en milieu de soins continus plus complexes dans plusieurs juridictions canadiennes. Méthode : Nous avons effectué une étude transversale au moyen de l'Instrument d'évaluation des résidents (IÉR 2,0 et IÉR soins à domicile) dans des bases de données nationales de 1996 à 2011. Le profil des patients atteints de SLA a été comparé à celui de patients sans problème neurologique prédéterminé. Résultats : Nous avons identifié 2092 patients atteints de SLA. Les individus atteints de SLA étaient plus susceptibles que ceux du groupe témoin d'avoir un état de santé instable $(25,4 \%)$ et des symptômes dépressifs allant de mineurs à majeurs $(27,2 \%)$, de présenter des chutes $(44,0 \%)$, de perdre du poids $(22,9 \%)$, d'avoir besoin de beaucoup d'aide pour les activités de la vie quotidienne (54,9\%) et de recevoir des services de réadaptation : réadaptation physique (23,9\%), orthophonie $(8,9 \%)$ et ergothérapie $(43,3 \%)$. Conclusions : La population de patients atteints de SLA est très touchée par plusieurs problèmes de santé. Ces patients sont plus susceptibles que ceux du groupe témoin d'avoir besoin de différents traitements, interventions médicales et médicaments psychotropes. Bien que le pronostic soit réservé chez ces patients, il y a beaucoup à faire pour rehausser leur qualité de vie et la qualité des soins qu'ils reçoivent.

Can J Neurol Sci. 2014; 41: 246-252

Amyotrophic lateral sclerosis (ALS) is a fatal degenerative disease involving motor neurons in the brain and spinal cord ${ }^{1-3}$. The annual age-adjusted incidence rate for ALS is about 2 per 100,000 in Canada ${ }^{4}$. Similar estimates are reported for Europe ${ }^{5}$. The age of onset of ALS symptoms is between 40-70 years ${ }^{3}$ with reported peaks at 47-52 years and 58-63 for familial and sporadic disease, respectively"1, and it is more common in $\operatorname{men}^{1,3}$.

Amyotrophic lateral sclerosis primarily results in physical disability, but can also cause behavioural and cognitive impairment ${ }^{6,7}$. Depression, anxiety and sleep disorders are common $^{1,8}$. It is a fatal disease (typically due to respiratory failure) with average survival of three to five years from the onset of symptoms based on clinic experience ${ }^{1,3}$.

Large scale studies of persons with ALS across the continuum of care are scarce. To provide appropriate care and treatment for persons with ALS, it is necessary to have a comprehensive understanding of the characteristics of persons with ALS across care settings. This knowledge is particularly important considering how disabling ALS is. This study aims to provide a comprehensive profile of the socio-demographic, clinical characteristics, and health resource utilization of three distinct groups of persons with ALS, that is those in: (1) home care (HC); (2) nursing homes (NH); and (3) and complex continuing

From the School of Public Health \& Health Systems (VK, JPH), University of Waterloo, Waterloo, Ontario; Department of Clinical Neurosciences and Hotchkiss Brain Institute (LK, NJ), Department of Community Health Sciences and Institute for Public Health ((LK, NJ), University of Calgary -Qatar (VK), Calgary, Alberta, Canada. Received May 8, 2013. Final Revisions Submitted SePtember 30, 2013. Correspondence to: Vahe Kehyayan, School of Public Health and Health Systems, University of Waterloo, 200 University Avenue West, Waterloo, Ontario, N2L 3G1, Canada. Email: vkehyaya@uwaterloo.ca. 
care (CCC) hospitals/units compared to persons without ALS or selected neurological conditions.

\section{Methods}

\section{Design, Sample and Source of Data}

This cross-sectional study forms an integral part of interRAI Canada's initiative, "Innovations in Data, Evidence and Applications for Persons with Neurological Conditions" (ideas PNC). This larger initiative aims at identifying the prevalence, profile and needs of persons with neurological conditions, such as ALS, dementia, epilepsy, multiple sclerosis, and stroke across the care continuum (http://interraicanada.uwaterloo.ca/).

The sample for this study was drawn from two large clinical databases: The Complex Continuing Care Reporting System (CCRS) and the Ontario Association of Community Care Access Centers (OACCAC) database.

The CCRS is managed by the Canadian Institute for Health Information and contains data on demographic, clinical, functional characteristics and resource use on persons receiving continuing care in either CCC hospitals/units or $\mathrm{NH}$ settings ${ }^{9}$. In both settings, interRAI's Resident Assessment Instrument 2.0 (RAI 2.0) is used as the standard assessment in normal clinical practice (www.interRAI.org). Only Ontario and Manitoba have CCC hospitals/units. In Ontario (173 CCC hospitals/unit), the CCRCS database includes quarterly and full RAI 2.0 assessments from April 10, 1996 to March 31, 2011. In Manitoba (one CCC hospital), where RAI assessments began in July 1, 2008, the data covers the period from July 1, 2008 to March 31, 2011.

The NH data include quarterly and full annual RAI 2.0 assessments over different time periods: Ontario (635 facilities) and Nova Scotia (8 facilities) from July 1, 2003 to March 31, 2011; British Columbia (126 facilities) from July 1, 2006 to March 31, 2011; Manitoba (38 facilities), Newfoundland (seven facilities), Saskatchewan (168 facilities), and Yukon Territory (two facilities) from July 1 to March 31, 2011. RAI 2.0 has been fully implemented in Ontario and Yukon, whereas its implementation is still underway in the other provinces.

The OACCAC database contains demographic, clinical, functional characteristics and service use data for persons in Ontario only who are expected to be receiving home care services for 60 days or more using interRAI's Resident Assessment Instrument-Home Care (RAI-HC) ${ }^{10}$. The home care RAI assessments are conducted twice yearly and include full assessments of persons residing in the community from January 1, 2002 to December 31, 2010.

For the purposes of this study, the most recent RAI 2.0 and RAI-HC assessments were used.

\section{Ethics Approval}

The ideasPNC research project received ethics approval from the Office of Research Ethics, University of Waterloo (Project \#17045).

\section{Case Ascertainment}

The diagnostic coding for ALS was based on written text in the OACCAC database. To obtain accurate diagnostic information from free text entry fields, a detailed iterative process was undertaken. Initially, neurological experts provided lists of free texts used in clinical practice to identify all the neurological conditions of interest. Then, analysts searched the database for similar key words and identified additional similar terms for verification by the neurologists for possible inclusion. Finally, based on an approved list of terms, a macro was applied to pick out each client with a given free text diagnosis (if applicable) and assign the appropriate diagnosis in the final dataset.

In the CCRS database, "Amyotrophic Lateral Sclerosis" was selected from a pick list of diagnoses provided in the RAI 2.0 form. The interRAI assessment instruments used in the three databases do not provide specific diagnostic information on frontotemporal dementia (FTD) and, thus, our ALS data do not specify FTD diagnosis.

Gambassi and colleagues (1998) reported high positive predictive values for neurological diagnoses in the RAI 2.0 when linked with other clinical datasets ${ }^{11}$. Similar findings were reported in a Canadian study on diagnostic coding in patients admitted to CCC hospitals/units from acute care ${ }^{12}$. However, neither of these studies included ALS as a diagnosis.

The profile of persons with ALS was examined relative to a comparison group that included patients without ALS or any of the following pre-specified neurological conditions identified using a combination of written texts, pick lists and ICD-10-CA codes: Alzheimer's disease/other dementias, epilepsy, cerebral palsy, Huntington's disease, multiple sclerosis, muscular dystrophy, Parkinson's disease, stroke, spinal cord injury, and traumatic brain injury.

\section{Clinical Measures}

The interRAI family of assessment instruments offers a system of integrated health information on individuals' performance in terms of their physical, psychosocial and cognitive function, health status, and treatments or interventions needed ${ }^{13}$. The suite of assessment instruments includes a variety of clinical scales, such as the Cognitive Performance Scale $(\mathrm{CPS})^{14}$, the Depression Rating Scale (DRS) ${ }^{15}$, the Changes in Health, End Stage Disease and Signs and Symptoms (CHESS) Scale $^{16}$, the Activities of Daily Living Hierarchy Scale $(\mathrm{ADLH})^{17}$, the Aggressive Behaviour Scale $(\mathrm{ABS})^{18}$, the Pain Scale $^{19}$ and the Instrumental Activities of Daily Living Scale $(\mathrm{IADL})^{20}$. The reliability and validity of the interRAI instruments have been widely demonstrated ${ }^{21-24}$.

\section{Analysis}

All analyses of the results were conducted using SAS version 9.2, SAS Institute Inc., Cary, North Carolina (http://www.sas.com/). Descriptive analyses were conducted to describe the profiles of persons with ALS and those of persons in the comparison group. Chi-square tests of significance were calculated to compare diagnostic groups (ALS vs. comparison group) within each of the three care sectors. Significance was assumed at the $\mathrm{p}<0.05$ level. 


\section{Table 1: Demographic Profile of Patients with Amyotrophic Lateral Sclerosis (ALS) and those in the Comparison Group $^{\wedge}$}

\begin{tabular}{lcccccc}
\hline \multirow{2}{*}{ Demographic Characteristics } & \multicolumn{2}{c}{ HC } & \multicolumn{2}{c}{ NH } & \multicolumn{2}{c}{ CCC } \\
\cline { 2 - 7 } & CG & ALS & CG & ALS & CG & ALS \\
\hline $\mathrm{N}$ & 320,581 & 1,454 & 51,000 & 247 & 95,338 & 391 \\
Female & $64.7 \%$ & $45.7 \%$ & $69.5 \%$ & $55.1 \%$ & $61.0 \%$ & $47.6 \%$ \\
Age Group & & & & & & \\
$45-54$ & $4.9 \%$ & $5.6 \%$ & $0.7 \%$ & $2.8 \%$ & $2.0 \%$ & $4.6 \%$ \\
$55-64$ & $6.6 \%$ & $14.4 \%$ & $1.6 \%$ & $9.3 \%$ & $3.9 \%$ & $11.0 \%$ \\
$65-74$ & $11.1 \%$ & $26.2 \%$ & $4.4 \%$ & $10.5 \%$ & $8.7 \%$ & $23.0 \%$ \\
$75-84$ & $16.6 \%$ & $29.3 \%$ & $9.3 \%$ & $23.5 \%$ & $19.4 \%$ & $25.6 \%$ \\
$85+$ & $31.6 \%$ & $20.9 \%$ & $26.5 \%$ & $28.3 \%$ & $36.7 \%$ & $27.9 \%$ \\
Married & $29.3 \%$ & $3.6 \%$ & $57.5 \%$ & $25.5 \%$ & $29.4 \%$ & $7.9 \%$ \\
Male & & & & & & \\
Female & & & & & & \\
Overall & $56.3 \%$ & $76.8 \%$ & $23.3 \%{ }^{\text {ns }}$ & $20.7 \%$ & $45.4 \%$ & $42.0 \%$ \\
Diagnosis & $29.4 \%$ & $56.9 \%$ & $8.0 \%^{*}$ & $16.9 \%$ & $22.5 \%$ & $30.1 \%$ \\
Heart Failure & $38.9 \%$ & $67.7 \%$ & $12.7 \%{ }^{*}$ & $18.6 \%$ & $31.5 \%$ & $36.3 \%{ }^{\text {ns }}$ \\
Emphysema/COPD & & & & & & \\
Diabetes & $13.5 \%$ & $1.7 \%$ & $19.7 \%$ & $6.2 \%$ & $15.8 \%$ & $4.1 \%$ \\
Cancer & $18.6 \%$ & $7.8 \%$ & $19.5 \%$ & $13.2 \%$ & $18.5 \%$ & $6.2 \%$ \\
Any psychiatric & $24.9 \%$ & $9.7 \%$ & $24.7 \%$ & $15.8 \%$ & $22.9 \%$ & $15.9 \%$ \\
Other CVD & $24.2 \%$ & $3.7 \%$ & $13.0 \%$ & $5.8 \%$ & $36.0 \%$ & $7.5 \%$ \\
\hline & $22.9 \%$ & $31.9 \%$ & $48.5 \%$ & $56.3 \%$ & $36.6 \%$ & $60.9 \%$ \\
& $63.5 \%$ & $36.9 \%$ & $60.6 \%$ & $46.9 \%$ & $48.5 \%$ & $34.7 \%$ \\
\hline
\end{tabular}

COPD $=$ Chronic Obstructive Pulmonary Disease $\mathrm{CVD}=$ Cardiovascular Disease. $\mathrm{HC}=$ Home Care. $\mathrm{NH}=$ Nursing Home. $\mathrm{CCC}=$ Complex

Continuing Care. $\mathrm{CG}=$ Comparison Group. ${ }^{\wedge}$ The Comparison Group comprises persons without any of the following neurological conditions: Alzheimer's disease/other dementias, Cerebral Palsy, Epilepsy, Huntington's Disease, Multiple Sclerosis, Muscular Dystrophy, Parkinson's Disease, Stroke, Spinal Cord injury, and Traumatic Brain Injury. Unless otherwise noted, the p values for chi-square tests of significance in this table are less than or equal to .0001 for tables comparing diagnostic groups within sectors. The symbol "ns" refers to values that are not significant at the .05 level and "*" denotes those that have significant $\mathrm{p}$ values below .05 but above .0001 .

\section{RESULTS}

\section{Sample Size}

In the three care settings, the sample of persons with ALS in this study was 2,092 with $69.5 \%(\mathrm{n}=1,454)$ of cases in $\mathrm{HC}$, $11.8 \%(\mathrm{n}=247)$ in $\mathrm{NH}$, and $18.7 \% \quad(\mathrm{n}=391)$ in CCC hospitals/units. The ALS sample of 2,092 comprised $0.23 \%$ of the total number of individuals with one of the pre-specified neurological conditions in all three settings $(\mathrm{N}=892,312)$. The comparison group $(n=466,919)$ comprised all persons without any of the pre-specified neurological conditions (see above). All comparisons described in this paper are significant at the $\mathrm{p}<$ 0.05 level (unless otherwise specified).

\section{Demographic Characteristics}

Table 1 provides the basic demographic and diagnostic information for ALS patients and the comparison group. In all
Table 2: Profile of Functional Performance of Patients with Amyotrophic Lateral Sclerosis (ALS) and those in the Comparison Group ${ }^{\wedge}$

\begin{tabular}{|c|c|c|c|c|c|c|}
\hline \multirow[t]{2}{*}{ Functional Performance } & \multicolumn{2}{|c|}{$\mathrm{HC}$} & \multicolumn{2}{|c|}{ NH } & \multicolumn{2}{|c|}{$\mathrm{CCC}$} \\
\hline & CG & ALS & CG & ALS & CG & ALS \\
\hline $\begin{array}{l}\mathbf{N} \\
\text { Cognitive Performance Scale }\end{array}$ & 320,581 & 1,454 & 51,000 & 247 & 95,338 & 391 \\
\hline 0 (Intact) & $63.5 \%$ & $55.6 \%$ & $32.6 \%$ & $31.6 \%$ & $34.3 \%$ & $24.3 \%$ \\
\hline $\begin{array}{l}\text { 1-2 (Borderline intact-mild } \\
\text { impairment }\end{array}$ & $33.1 \%$ & $36.3 \%$ & $35.6 \%$ & $28.7 \%$ & $35.2 \%$ & $36.6 \%$ \\
\hline $\begin{array}{l}\text { 3-4 (Moderate-Moderate severe } \\
\text { impairment) }\end{array}$ & $2.4 \%$ & $6.1 \%$ & $22.2 \%$ & $29.6 \%$ & $20.3 \%$ & $24.0 \%$ \\
\hline $\begin{array}{l}\text { 5-6 (Severe-Very severe } \\
\text { impairment) }\end{array}$ & $1.0 \%$ & $1.9 \%$ & $9.6 \%$ & $10.1 \%$ & $10.2 \%$ & $15.1 \%$ \\
\hline \multicolumn{7}{|l|}{ ADL Hierarchy Scale } \\
\hline 0 (Independent) & $73.1 \%$ & $22.9 \%$ & $11.9 \%$ & $2.4 \%$ & $8.5 \%$ & $2.8 \%$ \\
\hline $\begin{array}{l}\text { 1-2 (Supervision required- } \\
\text { limited impairment) }\end{array}$ & $18.1 \%$ & $22.2 \%$ & $23.7 \%$ & $8.9 \%$ & $24.9 \%$ & $4.3 \%$ \\
\hline $\begin{array}{l}3+(\text { Extensive assistance } \\
\text { required }- \text { total dependence })\end{array}$ & $8.8 \%$ & $54.9 \%$ & $64.4 \%$ & $88.7 \%$ & $66.6 \%$ & $92.8 \%$ \\
\hline \multicolumn{7}{|l|}{ Pain Scale } \\
\hline 0 (No pain) & $29.7 \%$ & $40.9 \%$ & $41.7 \%$ & $42.9 \%$ & $20.6 \%$ & $27.9 \%$ \\
\hline $\begin{array}{l}\text { 1-2 (Less than daily pain-Daily } \\
\text { pain not severe) }\end{array}$ & $54.7 \%$ & $47.9 \%$ & $52.3 \%$ & $51.0 \%$ & $66.7 \%$ & $64.7 \%$ \\
\hline $3+$ (Daily severe pain) & $15.6 \%$ & $11.1 \%$ & $6.0 \%$ & $6.1 \%$ & $12.7 \%$ & $7.4 \%$ \\
\hline \multicolumn{7}{|l|}{ CHESS Scale } \\
\hline 0 (Not at all unstable) & $31.2 \%$ & $10.2 \%$ & $39.0 \%$ & $36.4 \%$ & $15.8 \%$ & $14.6 \%$ \\
\hline $\begin{array}{l}\text { 1-2 (Little } \\
\text { - Some instability) }\end{array}$ & $54.4 \%$ & $64.4 \%$ & $47.1 \%$ & $47.4 \%$ & $42.1 \%$ & $47.1 \%$ \\
\hline $\begin{array}{l}3+\text { (Moderately } \\
\text {-Highly unstable) }\end{array}$ & $14.4 \%$ & $25.4 \%$ & $14.0 \%$ & $16.2 \%$ & $42.1 \%$ & $38.4 \%$ \\
\hline \multicolumn{7}{|l|}{ IADL Items } \\
\hline Any Impaired IADL & $86.5 \%$ & $97.0 \%$ & $\mathrm{n} / \mathrm{a}$ & $\mathrm{n} / \mathrm{a}$ & $\mathrm{n} / \mathrm{a}$ & $\mathrm{n} / \mathrm{a}$ \\
\hline Meal Preparation & $77.9 \%$ & $95.3 \%$ & $\mathrm{n} / \mathrm{a}$ & $\mathrm{n} / \mathrm{a}$ & $\mathrm{n} / \mathrm{a}$ & $\mathrm{n} / \mathrm{a}$ \\
\hline Managing Finances & $53.3 \%$ & $74.9 \%$ & $\mathrm{n} / \mathrm{a}$ & $\mathrm{n} / \mathrm{a}$ & $\mathrm{n} / \mathrm{a}$ & $\mathrm{n} / \mathrm{a}$ \\
\hline Managing Medications & $41.3 \%$ & $70.5 \%$ & $\mathrm{n} / \mathrm{a}$ & $\mathrm{n} / \mathrm{a}$ & $\mathrm{n} / \mathrm{a}$ & $\mathrm{n} / \mathrm{a}$ \\
\hline Transportation & $66.6 \%$ & $87.4 \%$ & $\mathrm{n} / \mathrm{a}$ & $\mathrm{n} / \mathrm{a}$ & $\mathrm{n} / \mathrm{a}$ & $\mathrm{n} / \mathrm{a}$ \\
\hline
\end{tabular}

IADL=Instrumental Activities of Daily Living. $\mathrm{HC}=$ Home Care $. \mathrm{NH}=$ Nursing Home. $\mathrm{CCC}=$ Complex Continuing Care. $\mathrm{CG}=$ Comparison Group. NA=Not Available. ^ ${ }^{\wedge}$ The Comparison Group (CG) comprises persons without any of the following neurological conditions: Alzheimer's disease/other dementias, Cerebral Palsy, Epilepsy, Huntington's Disease, Multiple Sclerosis, Muscular Dystrophy, Parkinson's Disease, Stroke, Spinal Cord injury, and Traumatic Brain Injury. Unless otherwise noted, the p values for chi-square tests of significance in this table are less than or equal to .0001 for tables comparing diagnostic groups within sectors. The symbol "ns" refers to values that are not significant at the .05 level.

three settings, those with ALS were less likely to be female consistent with other reports that the incidence of ALS is more frequent in men with a ratio of $3: 2^{3}$. Those with ALS were generally younger than the comparison group. Except for those in CCC settings, persons with ALS were more likely to be married than those in the comparison group.

In all three settings, persons with ALS were less likely to have one of the somatic comorbidities examined but more were more likely to have "any psychiatric diseases" (including anxiety 
and depressive symptoms, delusions and hallucinations) than the comparison group.

\section{Clinical and Functional Profile}

Table 2 shows the distributions of clinical scales available in each of the interRAI assessments. In all three settings, persons with ALS were more likely than those in the comparison group to have moderate to severe cognitive impairment (CPS scores of 3 - 6) with increasing prevalence across the more resource intensive care settings ( $\mathrm{HC} \rightarrow \mathrm{NH} \rightarrow \mathrm{CCC}$ ). Functionally, persons with ALS were more likely than the comparison group to require extensive assistance or to be totally dependent (ADLH scores of $3+$ ).

In all settings, persons with ALS were less likely to have pain but more likely to have high health instability (CHESS scores of $3+)$ than the comparison group.

\section{Health and Social-Economic Profile}

Table 3 shows the health, social and economic profiles of the study sample. Those with ALS in HC settings were more likely to experience higher rates of falls than the comparison group despite increased wheelchair use. Persons with ALS were less likely than the comparison group to walk and bathe independently in all settings. Also, those with ALS in $\mathrm{NH}$ settings were substantially more likely to have pressure ulcers, and they were much more likely to have swallowing problems than the comparison group in all settings. In HC, persons with ALS were more likely than the comparison group to report fair/poor health. Persons with ALS in all settings also had higher rates of bowel incontinence, while those in $\mathrm{NH}$ and CCC settings were more likely to have bladder incontinence than the comparison group. In all settings, the ALS group was more likely to have unintended weight loss of $5 \%$ or more in last 30 days or $10 \%$ or more in the last 180 days than the comparison group. Except for those in CCC settings, the ALS group was more likely than the comparison group to show a noticeable decrease in the amount of food or fluid intake. With respect to IADL, persons with ALS in HC settings were more likely to have any IADL impairments than the comparison group. In terms of communication issues, the ALS group was much more likely than the comparison group in all three settings to experience communication impairments, including expression and comprehension.

Those with ALS were also more likely than the comparison group to exhibit moderate or worse depressive symptoms (DRS scores of $3+$ ) or anxiety symptoms than the comparison group. Only those with ALS in NH settings were more likely to manifest aggressive behaviours than the comparison group; however, the rate of aggressive behaviour for persons with ALS was much higher in facility-based settings than in HC settings. In all three settings, persons with ALS were more likely than the comparison group to have been physically restrained and received antidepressants and anxiolytics. The ALS group in CCC settings also was more likely to receive sedatives than the comparison group.

With respect to social and economic issues, those with ALS in $\mathrm{HC}$ and CCC settings were more likely to experience conflict with others than the comparison group. In all settings, those with ALS were less likely to experience social isolation than the
Table 3: Health, Social and Economic Profile of Patients with Amyotrophic Lateral Sclerosis (ALS) and those in the Comparison Group $\wedge$

\begin{tabular}{|c|c|c|c|c|c|c|}
\hline \multirow[t]{2}{*}{ Health, Social and Economic Profile } & \multicolumn{2}{|c|}{$\mathrm{HC}$} & \multicolumn{2}{|c|}{ NH } & \multicolumn{2}{|c|}{$\mathrm{CCC}$} \\
\hline & CG & ALS & CG & ALS & CG & ALS \\
\hline $\begin{array}{l}\mathbf{N} \\
\text { Health Issues }\end{array}$ & 320,581 & 1,454 & 51,000 & 247 & 95,338 & 391 \\
\hline Fell in last 90 days & $28.8 \%$ & $44.0 \%$ & $14.8 \%$ & $13.0 \%$ & $24.5 \%$ & $11.0 \%$ \\
\hline Unsteady gait & $54.6 \%$ & $70.9 \%$ & $35.0 \%$ & $29.1 \%$ & $42.4 \%$ & $23.3 \%$ \\
\hline Shortness of breath & $28.0 \%$ & $29.8 \%$ & $18.3 \%$ & $17.8 \%$ & $32.9 \%$ & $39.9 \%$ \\
\hline Loss of appetite & $12.8 \%$ & $11.8 \%$ & $29.2 \%$ & $32.0 \%$ & $39.1 \%$ & $30.2 \%$ \\
\hline Pressure ulcers & $9.0 \%$ & $7.2 \%$ & $8.3 \%$ & $9.3 \%$ & $14.5 \%$ & $21.2 \%$ \\
\hline Trouble swallowing & $6.5 \%$ & $60.8 \%$ & $13.0 \%$ & $51.8 \%$ & $18.6 \%$ & $75.4 \%$ \\
\hline Weight loss & $11.4 \%$ & $22.9 \%$ & $11.4 \%$ & $16.2 \%$ & $17.3 \%$ & $20.7 \%$ \\
\hline Nutritional problems & $4.2 \%$ & $6.9 \%$ & $29.2 \%$ & $32.0 \%$ & $39.1 \%$ & $30.2 \%$ \\
\hline Fair/Poor self-rated health & $22.7 \%$ & $35.7 \%$ & $\mathrm{n} / \mathrm{a}$ & $\mathrm{n} / \mathrm{a}$ & $\mathrm{n} / \mathrm{a}$ & $\mathrm{n} / \mathrm{a}$ \\
\hline \multicolumn{7}{|l|}{ Occasional/worse Incontinence } \\
\hline Bladder & $20.2 \%$ & $17.5 \%$ & $53.9 \%$ & $58.7 \%$ & $32.9 \%$ & $40.9 \%$ \\
\hline Bowel & $6.1 \%$ & $9.5 \%$ & $26.9 \%$ & $36.8 \%$ & $27.4 \%$ & $48.1 \%$ \\
\hline \multicolumn{7}{|l|}{ Communication Impairments } \\
\hline Expression & $3.0 \%$ & $21.7 \%$ & $9.8 \%$ & $26.7 \%$ & $11.6 \%$ & $38.6 \%$ \\
\hline Comprehension & $3.7 \%$ & $4.1 \%$ & $10.8 \%$ & $12.6 \%$ & $14.1 \%$ & $18.2 \%$ \\
\hline \multicolumn{7}{|l|}{ Mobility } \\
\hline Uses wheelchair & $6.8 \%$ & $36.7 \%$ & $56.7 \%$ & $73.1 \%$ & $44.7 \%$ & $67.5 \%$ \\
\hline Walks independently & $35.1 \%$ & $13.8 \%$ & $25.0 \%$ & $10.1 \%$ & $13.6 \%$ & $5.9 \%$ \\
\hline Bathes independently & $33.8 \%$ & $13.7 \%$ & $1.3 \%$ & $1.2 \%$ & $5.0 \%$ & $1.8 \%$ \\
\hline \multicolumn{7}{|l|}{ Mental Health } \\
\hline Anxiety Symptoms & $12.8 \%$ & $15.0 \%$ & $34.3 \%$ & $39.7 \%$ & $23.4 \%$ & $34.8 \%$ \\
\hline Delirium & $2.9 \%$ & $1.6 \%$ & $9.9 \%$ & $9.7 \%$ & $16.7 \%$ & $16.1 \%$ \\
\hline Any Aggressive Behaviour & $3.3 \%$ & $3.0 \%$ & $27.1 \%$ & $33.2 \%$ & $20.3 \%$ & $21.0 \%$ \\
\hline Hallucinations/Delusions & $1.5 \%$ & $0.6 \%$ & $3.8 \%$ & $2.4 \%$ & $5.3 \%$ & $2.6 \%$ \\
\hline \multicolumn{7}{|l|}{ Depression } \\
\hline 0 (Not depressed) & $63.6 \%$ & $46.6 \%$ & $42.6 \%$ & $33.5 \%$ & $50.7 \%$ & $32.0 \%$ \\
\hline $\begin{array}{l}1-2 \text { (Some depressive } \\
\text { symptoms) }\end{array}$ & $22.0 \%$ & $26.3 \%$ & $29.5 \%$ & $28.2 \%$ & $28.6 \%$ & $29.2 \%$ \\
\hline $\begin{array}{l}3+(\text { Potential minor } \\
- \text { Major depressive episode })\end{array}$ & $14.5 \%$ & $27.2 \%$ & $27.9 \%$ & $38.4 \%$ & $20.8 \%$ & $38.8 \%$ \\
\hline Physical Restraint Use & $0.2 \%$ & $1.0 \%$ & $8.4 \%$ & $16.6 \%$ & $9.2 \%$ & $14.1 \%$ \\
\hline \multicolumn{7}{|l|}{ Psychotropic Drug Use } \\
\hline Antipsychotics & $5.6 \%$ & $4.1 \%$ & $20.2 \%$ & $15.4 \%$ & $14.6 \%$ & $13.8 \%$ \\
\hline Antidepressants & $19.9 \%$ & $30.6 \%$ & $41.0 \%$ & $51.4 \%$ & $25.3 \%$ & $52.7 \%$ \\
\hline Anxiolytics & $17.4 \%$ & $19.1 \%$ & $19.6 \%$ & $32.4 \%$ & $34.6 \%$ & $48.3 \%$ \\
\hline Sedatives & $14.3 \%$ & $12.9 \%$ & $12.5 \%$ & $10.1 \%$ & $15.7 \%$ & $23.3 \%$ \\
\hline \multicolumn{7}{|l|}{ Social \& Economic Issues } \\
\hline Made economic trade-offs $\dagger$ & $2.3 \%$ & $2.5 \%$ & $\mathrm{n} / \mathrm{a}$ & $\mathrm{n} / \mathrm{a}$ & $\mathrm{n} / \mathrm{a}$ & $\mathrm{n} / \mathrm{a}$ \\
\hline Conflict with others & $11.1 \%$ & $12.2 \%$ & $13.9 \%$ & $14.8 \%^{\mathrm{ns}}$ & $11.8 \%$ & $18.3 \%$ \\
\hline Social Isolation & $18.8 \%$ & $6.3 \%$ & $5.0 \%$ & $2.3 \%$ & $6.2 \%$ & $4.1 \%$ \\
\hline Caregivers distressed/overwhelmed & $12.8 \%$ & $29.4 \%$ & $\mathrm{n} / \mathrm{a}$ & $\mathrm{n} / \mathrm{a}$ & $\mathrm{n} / \mathrm{a}$ & $\mathrm{n} / \mathrm{a}$ \\
\hline
\end{tabular}

$\mathrm{HC}=$ Home Care. $\mathrm{NH}=$ Nursing Home. $\mathrm{CCC}=$ Complex Continuing Care. $\mathrm{CG}=$ Comparison Group. NA=Not Available. ${ }^{\wedge}$ The Comparison Group comprises persons without any of the following neurological conditions: Alzheimer's disease/other dementias, Cerebral Palsy, Epilepsy, Huntington's Disease, Multiple Sclerosis, Muscular Dystrophy, Parkinson's Disease, Stroke, Spinal Cord injury, and Traumatic Brain Injury. Unless otherwise noted, the p values for chisquare tests of significance in this table are less than or equal to .0001 for tables comparing diagnostic groups within sectors. The symbol "ns" refers to values that are not significant at the .05 level. $\dagger$ Because of limited funds, during the last 30 days, the patient made trade-offs among purchasing adequate food, shelter, clothing, prescribed medications, sufficient home heat or cooling, OR necessary health care. 


\section{Table 4: Health Resource Utilization of Patients with Amyotrophic Lateral Sclerosis (ALS) and those in the Comparison Group ${ }^{\wedge}$}

\begin{tabular}{|c|c|c|c|c|c|c|}
\hline \multirow[t]{2}{*}{ Health Resource } & \multicolumn{2}{|c|}{ HC } & \multicolumn{2}{|c|}{ NH } & \multicolumn{2}{|c|}{$\mathrm{CCC}$} \\
\hline & $\mathbf{C G}$ & ALS & CG & ALS & CG & $\mathbf{A L S}$ \\
\hline $\mathbf{N}$ & 320,581 & 1,454 & 51,000 & 247 & 95,338 & 391 \\
\hline \multicolumn{7}{|l|}{ Any Rehabilitation } \\
\hline Physical Therapy & $12.2 \%$ & $23.9 \%$ & $55.1 \%$ & $64.0 \%$ & $63.2 \%$ & $61.6 \%$ \\
\hline Occupational Therapy & $10.7 \%$ & $43.3 \%$ & $4.8 \%$ & $4.9 \%$ & $47.4 \%$ & $55.8 \%$ \\
\hline Speech Language Pathology & $0.3 \%$ & $8.9 \%$ & $0.2 \%$ & $1.6 \%$ & $6.5 \%$ & $27.9 \%$ \\
\hline Social Work/Psychologist & $1.6 \%$ & $7.0 \%$ & $1.4 \%$ & $1.2 \%{ }^{\mathrm{ns}}$ & $11.7 \%$ & $15.6 \%$ \\
\hline Psychiatrist & $\mathrm{n} / \mathrm{a}$ & $\mathrm{n} / \mathrm{a}$ & $\mathrm{n} / \mathrm{a}$ & $\mathrm{n} / \mathrm{a}$ & $\mathrm{n} / \mathrm{a}$ & $\mathrm{n} / \mathrm{a}$ \\
\hline Other physician visits & $36.7 \%$ & $39.1 \%$ & $66.8 \%$ & $68.4 \%$ & $93.4 \%$ & $93.9 \%$ * \\
\hline Personal Support/Homemaking & $55.7 \%$ & $0.0 \%$ & $\mathrm{n} / \mathrm{a}$ & $\mathrm{n} / \mathrm{a}$ & $\mathrm{n} / \mathrm{a}$ & $\mathrm{n} / \mathrm{a}$ \\
\hline Recreation therapy & $\mathrm{n} / \mathrm{a}$ & $\mathrm{n} / \mathrm{a}$ & $12.2 \%$ & $15.0 \%$ & $31.3 \%$ & $30.9 \%$ \\
\hline \multicolumn{7}{|l|}{ Medical Interventions } \\
\hline Respirator/other device & $0.4 \%$ & $6.1 \%$ & $0.3 \%$ & $4.5 \%$ & $0.5 \%$ & $19.2 \%$ \\
\hline Oxygen/Respiratory therapy & $10.3 \%$ & $16.5 \%$ & $11.6 \%$ & $17.0 \%$ & $27.4 \%$ & $39.9 \%$ \\
\hline Intravenous & $4.9 \%$ & $1.7 \%$ & $2.0 \%$ & $4.0 \%$ & $12.7 \%$ & $10.0 \%$ \\
\hline Nurse monitoring & $38.3 \%$ & $35.5 \%$ & $\mathrm{n} / \mathrm{a}$ & $\mathrm{n} / \mathrm{a}$ & $\mathrm{n} / \mathrm{a}$ & $\mathrm{n} / \mathrm{a}$ \\
\hline Enteral/Tube feeding & $1.0 \%$ & $21.5 \%$ & $0.9 \%$ & $19.4 \%$ & $2.9 \%$ & $45.5 \%$ \\
\hline Tracheostomy care & $0.3 \%$ & $2.1 \%$ & $0.2 \%$ & $2.8 \%$ & $1.1 \%$ & $17.4 \%$ \\
\hline Wound care & $27.0 \%$ & $34.1 \%$ & $20.7 \%$ & $27.1 \%$ & $39.5 \%$ & $37.1 \%$ \\
\hline \multicolumn{7}{|l|}{ Emergency Department Visits } \\
\hline None & $78.6 \%$ & $85.7 \%$ & $79.9 \%$ & $85.4 \%$ & $54.4 \%$ & $67.5 \%$ \\
\hline 1 & $15.8 \%$ & $11.6 \%$ & $17.1 \%$ & $13.8 \%$ & $36.5 \%$ & $26.7 \%$ \\
\hline $2+$ & $5.6 \%$ & $2.7 \%$ & $3.0 \%$ & $0.8 \%$ & $9.1 \%$ & $5.8 \%$ \\
\hline \multicolumn{7}{|l|}{ Hospitalizations } \\
\hline None & $64.7 \%$ & $81.4 \%$ & $82.4 \%$ & $88.1 \%$ & $38.8 \%$ & $68.1 \%$ \\
\hline 1 & $29.2 \%$ & $17.0 \%$ & $15.6 \%$ & $11.9 \%$ & $43.0 \%$ & $24.9 \%$ \\
\hline $2+$ & $6.1 \%$ & $1.7 \%$ & $2.0 \%$ & $0.0 \%$ & $18.2 \%$ & $6.9 \%$ \\
\hline
\end{tabular}

$\mathrm{HC}=$ Home Care. $\mathrm{NH}=$ Nursing Home $. \mathrm{CCC}=$ Complex Continuing Care. $\mathrm{CG}=$ Comparison Group. NA=Not Available. ${ }^{\wedge}$ The Comparison Group comprises persons without any of the following neurological conditions: Alzheimer's disease/other dementias, Cerebral Palsy, Epilepsy, Huntington's Disease, Multiple Sclerosis, Muscular Dystrophy, Parkinson's Disease, Stroke, Spinal Cord injury, and Traumatic Brain Injury. Unless otherwise noted, the $\mathrm{p}$ values for chisquare tests of significance in this table are less than or equal to .0001 for tables comparing diagnostic groups within sectors. The symbol "ns" refers to values that are not significant at the .05 level and "*" denotes those that have significant $\mathrm{p}$ values below .05 but above .0001 .

comparison group. In HC settings, caregivers of persons with ALS were more likely than caregivers of persons in the comparison group to be distressed or overwhelmed.

\section{Health Resource Utilization}

Table 4 shows the health resource utilization of the study sample. Those in $\mathrm{HC}$ settings were more likely than the comparison group to receive all of the rehabilitation services or therapies listed. Those in CCC settings were more likely than the comparison group to receive occupational, speech language pathology, and social work/psychologist services/therapies. In all settings, the ALS group was more likely than the comparison group to receive oxygen/respiratory therapy, make use of a respirator or other devices, receive tube feeding and tracheostomy care than the comparison group.

Despite their general higher scores on clinical and functional indicators in all three settings, the ALS group was less likely to have made emergency department visits or required hospitalizations than the comparison group.

\section{Discussion}

This very large and unique study, describing the sociodemographic and clinical characteristics and health resource utilization of persons with ALS across the continuum of care, may be the largest of its kind. Only a very small proportion of individuals with neurological conditions in the three study settings had a diagnosis of ALS consistent with the low prevalence of ALS in the general population. However, ALS is associated with substantial morbidity and mortality ${ }^{4}$. The widespread adoption of interRAI assessment instruments in Canadian provinces/territories has made it possible to obtain standardized clinical information for persons with ALS with sample sizes not typically seen in the literature. The important clinical differences among ALS populations in the three health care settings underscore the importance of having common, standardized function and clinical measures across the continuum of care. Although the ALS diagnosis points to a range of important clinical consequences for persons with the condition, the present findings demonstrate substantial heterogeneity within the ALS population between service settings.

Amyotrophic lateral sclerosis is an adult disease with an onset peak age between ages 55 and 74 . Within this age group, the majority of ALS patients remain in the community receiving home care. It is interesting to note that most of those in $\mathrm{HC}$ are married (67.7\%), which may suggest the important role that spousal support has in preventing institutional care. In contrast, only $18.6 \%$ of persons with ALS in NH are married.

A review of the clinical profile of the ALS group shows a severity gradient across the three settings. For instance, the highest proportion of ALS patients having any psychiatric comorbidities (Table 1) is situated in CCC (60.9\%) followed by $\mathrm{NH}(56.3 \%)$ and $\mathrm{HC}(31.9 \%)$. A similar gradient is also noted with depressive symptoms and functional impairments. The majority of ALS patients requiring extensive assistance or totally dependent are in $\mathrm{CCC}$, followed by $\mathrm{NH}$ and $\mathrm{HC}$, as would be expected with decreased levels of disability through this continuum of care. Persons with ALS in HC were more likely to have moderate to high health instability and to have self-rated their health as fair/poor compared. Since pain is not a primary symptom in ALS, it is not surprising that ALS patients were less likely to have pain. However, 59\% in HC, $57 \%$ in NH, and $72 \%$ in CCC reported having pain (less than daily to severe daily pain) highlighting the need to maintain a high index of suspicion for presence of pain symptoms in ALS patients. This finding is consistent with a prior study where $60 \%$ of ALS patients reported experiencing pain ${ }^{25}$.

The high rates of falls and unsteady gait in the study sample is expected, given that weakness is associated with ALS. Those in $\mathrm{HC}$ experienced higher rates of falls and unsteady gait compared to CCC and NH settings. It is not surprising that ALS patients in CCC and $\mathrm{NH}$ were more likely to be in wheelchairs than those in $\mathrm{HC}$, and those in $\mathrm{HC}$ were more likely to be able to walk independently. These findings suggest that as ALS patients become weaker and unable to walk independently their likelihood of requiring either $\mathrm{NH}$ or $\mathrm{CCC}$ for increased level of care and supervision increases.

As expected, ALS patients in this study were more likely to experience breathing difficulties ${ }^{1}$. Patients with ALS in CCC 
settings were most likely to have shortness of breath and, not surprisingly, were more likely to receive oxygen therapy and or require a ventilator than those in either $\mathrm{HC}$ or NH settings. It is not surprising that the rate of dysphagia was also higher in ALS patients in all three settings given that this is a common symptom seen in clinical practice ${ }^{1}$. An interesting finding was the higher rates of pressure ulcers in $\mathrm{NH}$ and CCC settings in ALS patients compared to the comparison group. While the development of pressure ulcers may be a rarity in ALS patients, the data show that the risk is present and clinicians should be mindful of it.

In this study, $21.7 \%$ of ALS patients experienced weight loss. This finding may be associated with loss of muscle bulk, or as a complication of breathing and swallowing difficulties. Other researchers have reported decrease in body fat, lean body mass and muscle power in those with $\mathrm{ALS}^{26}$. The results of the current study point to the need for appropriate management of ALS patients' nutrition, including an assessment by a nutritionist. Persons with ALS in this study also showed higher rates of bowel and bladder incontinence. This may relate to their being less likely to be independent in locomotion and greater overall ADL dependence.

Consistent with other research ${ }^{27}$, caregivers of ALS patients in the community were more likely to be distressed. Aside from the physical aspects of providing care to their family member who is affected by ALS, factors such as cognitive impairment, falls, and communication impairments may all contribute to caregivers' psychological distress.

It was interesting that the ALS group in all three settings was least likely to have made emergency department visits or required hospitalizations. This may be related to more access to a multidisciplinary team, including physical and speech therapists, and physicians. However, other research has shown inconsistent results of the benefits of multidisciplinary services in ALS patients ${ }^{28,29}$.

\section{STRENGTHS AND Limitations}

The use of validated national multi-jurisdiction clinical databases involving very large sample sizes is one of the strengths of this study. This study demonstrated the feasibility of using the interRAI suite of assessment instruments to assess the socio-demographic characteristics, health profiles and health resource utilization of people with ALS across the continuum of care.

This study also has a number of limitations. Its crosssectional design limited the ability to estimate the incidence of clinical change in ALS patients; however, future research may readily address this limitation by making use of the longitudinal assessment records available in the databases described here. Data were only collected in the participating Canadian provinces, but not in the rest of Canada where the interRAI assessment systems have not yet been implemented. As well, the study sample is limited to ALS patients who are accessing the health care settings studied, but there are no comparable data on those who may have undiagnosed ALS or those who are not yet receiving home care or more complex continuing care. An important opportunity to remedy this information gap would be to ensure that any registries developed for neurological conditions such as ALS include measures that would be compatible with the interRAI instruments already in widespread use to assess persons in HC, LTC and CCC settings. One other limitation is that the data available could not specify if patients with ALS also had FTD. Future studies should endeavour to secure such data.

\section{Conclusion}

In summary, the ALS population described in this study has exceptional needs that require substantial resources from service providers spanning the continuum of care. Clearly, persons with ALS are more likely to require therapies, medical interventions, and pharmacotherapies than the comparison group. The functional and clinical consequences of ALS also place a substantial psychological distress on caregivers. While persons with ALS have a poor general prognosis, a great deal could be done to potentially enhance specific aspects of their quality of care.

\section{ACKNOWLEDGMENTS}

This study is part of the National Population Health Study of Neurological Conditions. The authors wish to acknowledge the membership of Neurological Health Charities Canada and the Public Health Agency of Canada for their contribution to the success of this initiative.

Funding for the study was provided by the Public Health Agency of Canada, Project \#6271-15-2010/3970773. The opinions expressed in this publication are those of the authors/researchers, and do not necessarily reflect the official views of the Public Health Agency of Canada.

N. Jette holds a salary award from Alberta Innovates Health Solutions and a Canada Research Chair in Neurological Health Services Research. J. Hirdes holds the Ontario Home Care Research and Knowledge Exchange Chair funded by the Ontario Ministry of Health and Long Term Care.

\section{REFERENCES}

1. Kiernan $\mathrm{MC}$, Vucic $\mathrm{S}$, Cheah $\mathrm{BC}$, et al. Amyotrophic lateral sclerosis. Lancet. 2011;377:942-55.

2. Murray CA, editor. Amyotrophic lateral sclerosis. New York: Nova Science Publishers, Inc.; 2006.

3. Miller RG, Gelinas D, O'Connor P. Amyotrophic lateral sclerosis. New York: American Academy of Neurology; 2005.

4. Wolfson C, Kilborn S, Oskoui M, Genge A. Incidence and prevalence of amyotrophic lateral sclerosis in Canada: a systematic review of the literature. Neuroepidemiology. 2009; 33:79-88

5. Logroscino G, Traynor BJ, Hardiman $\mathrm{O}$, et al. Incidence of amyotrophic lateral sclerosis in Europe. J Neurol Neurosurg Psychiatry. 2010;81:385-90.

6. Abrahams S. Social cognition in amyotrophic lateral sclerosis. Neurodegener Dis Manag. 2011;1:397-405.

7. Phukan J, Elamin M, Bede P, et al. The syndrome of cognitive impairment in amyotrophic lateral sclerosis: a population-based study. J Neurol Neurosurg Psychiatry. 2012;83:102-8.

8. Atassi N, Cook A, Pineda CME, Yerramilli-Rao P, Pulley D, Cudkowicz M. Depression in amyotrophic lateral sclerosis. Amyotrop Lateral Scler. 2011;12:109-12.

9. Canadian Institute for Health Information. Continuing care reporting system metadata. [cited 2013 Feb 12] Available from: http://www.cihi.ca/CIHI-ext-portal/internet/en/document/ types+of+care/hospital+care/continuing+care/ccrs_metadata.

10. Canadian Institute for Health Information. Home care reporting system. [cited 2013 Feb 12] Available from: http://www.cihi.ca/cihi-ext-portal/internet/en/document/types+ of+care/community+care/home+care/hcrs_metadata. 
11. Gambassi G, Landi F, Peng L, et al. Validity of diagnostic and drug data in standardized nursing home resident assessments potential for geriatric pharmacoepidemiology. Med Care. 1998; 36(2):167-79.

12. Wodchis WP, Naglie G, Teare GF. Validating diagnostic information on the minimum data set in Ontario hospital-based long-term care. Med Care. 2008;46:882-7.

13. Gray LC, Berg K, Fries BE, et al. Sharing clinical information across care settings: the birth of an integrated assessment system. BMC Health Serv Res. [Published 2009 Apr 29];9:71. Available from http://www.biomedcentral.com/1472-6963/9/71.

14. Morris JN, Fries BE, Mehr DR, Hawes C. MDS cognitive performance scale®. J Gerontol. 1994;49:M174-82.

15. Burrows AB, Morris JN, Simon SE, Hirdes JP, Phillips C. Development of a minimum data set-based depression rating scale for use in nursing homes. Age Ageing. 2000;29:165-72.

16. Hirdes JP, Frijters DH, Teare GF. The MDS-CHESS scale: a new measure to predict mortality in institutionalized older people. $\mathrm{J}$ Am Geriatr Soc. 2003;51:96-100.

17. Morris JN, Fries BE, Morris SA. Scaling ADLs within the MDS. J Gerontol. 1999;54:M546-53.

18. Perlman CM, Hirdes JP. The aggressive behavior scale: a new scale to measure aggression based on the minimum data set. J Am Geriatr Soc. 2008;56:2298-303.

19. Fries BE, Simon SE, Morris JN. Pain in U.S. nursing homes: validating a pain scale for the minimum data set. Gerontologist. 2001;41:173-9.

20. Morris JN, Carpenter I, Berg K, Jones RN. Outcome measures for use with home care clients. Can J Aging. 2000;19:87-105.
21. Hirdes JP, Ljunggren G, Morris JN, et al. Reliability of the interRAI suite of assessment instruments: a 12-country study of an integrated health information system. BMC Health Serv Res. 2008;8:1-11.

22. Landi F, Tua E, Onder G, et al. Minimum data set for home care: a valid instrument to assess frail older people living in the community. Med Care. 2000;38:1184-90.

23. Morris JN, Fries BE, Steel K. Comprehensive clinical assessment in community setting: applicability of the MDS-HC. J Am Geriatr Soc. 1997;45:1017-24.

24. Poss JW, Jutan NM, Hirdes JP, et al. A review of evidence on the reliability and validity of minimum data set data. Healthc Manage Forum. 2008;21:33-9.

25. Jensen MP, Abresch RT, Carter GT, McDonald CM. Chronic pain in persons with neuromuscular disease. Arch Phys Med Rehabil. 2005;86:1155-63.

26. Kasarskis EJ, Berryman S, Vanderleest JG, Schneider AR, McClain CJ. Nutritional status of patients with amyotrophic lateral sclerosis: relation to the proximity of death. Am J Clin Nutr. 1996;63:130-7.

27. Gauthier A, Vignola A, Calvo A, et al. A longitudinal study on quality of life and depression in ALS patient-caregiver couples. Neurology. 2007;68:923-6.

28. Traynor BJ, Alexander M, Corr B, Frost E, Hardiman O. An outcome study of riluzole in amyotrophic lateral sclerosis--a population-based study in Ireland, 1996-2000. J Neurol. 2003; 250:473-9.

29. Zoccolella S, Beghi E, Palagano G, et al. ALS multidisciplinary clinic and survival. Results from a population-based study in Southern Italy. J Neurol. 2007;254:1107-12. 